\title{
Research Paper Construction of variance balanced designs using incidence matrix
}

See end of the paper for authors' affiliations

Correspondence to :

Rashmi Awad

School of Statistics, Devi Ahilya University, Indore (M.P.) India

Email: awad.rashmi@gmail. com

\section{Paper History :}

Received : 24.12.2019;

Revised : 17.02.2020;

Accepted : 24.02 .2020
ABSTRACT : A method of constructing variance balanced designs with unequal block sizes is proposed using incidence matrix, where no other design required. It is the extension to the method given by Rajarathinam et al. (2014). Further optimality of the constructed design has been checked and found it to be universally optimal.

KEY WORDS : Balanced incomplete block design, Variance balanced design, Universally optimal design

How To Cite This PAPer : Awad, Rashmi and Banerjee, Shakti (2020). Construction of variance balanced designs using incidence matrix. Internat. Res. J. Agric. Eco. \& Stat., 11 (1) : 102-108, DOI : 10.15740/HAS/ IRJAES/11.1/102-108. Copyright@2020:HindAgri-Horticultural Society. 